\title{
Excessive Extent in Cognition-A Contrastive Study on Mandarin and English
}

\author{
Hsiu-Ying Liu \\ Asia University, Taichung, Taiwan \\ Email: violet90@ms39.hinet.net \\ Cheng-Chung Kuo* \\ National Taichung University, Taichung, Taiwan \\ Email: eatonkuo@hotmail.com
}

\begin{abstract}
Every language has various ways to indicate excessive extent, and the adoption of degree adverbs is always the most popular, such as hen 很 $^{1}$, fei-chang 非常 in Mandarin and very in English. Mandarin uses excessive construction (e.g. $\mathrm{X}^{2}$-si, $\mathrm{X}$-bao, etc.) as well, and the predicate-complement expressions appear in modern colloquial Mandarin with a very high frequency because of popularity with the young generation. Coping with Mandarin excessive construction, the present paper first tries to figure out the possible generation linking excessive complements with excessive extent. Afterwards, English excessive degree adverbs would be examined to see if the generation works universally. It is our attempt to find out similar cognitive mappings in the two languages, which enables us to further propose RULEs in cognition. We think the cognitive rules might ease the semantic comprehension of a language, and a universal generation in cognition would benefit to foreign language teaching and learning.
\end{abstract}

Index Terms - excessive complement, excessive degree adverb, cognition

\section{INTRODUCTION}

EXTENT is somewhat an abstract concept; however, it appears to be the basic experience in human beings' conceptual structure. Extent seems to exist in our daily life, and everything bears a relation to it: the redness of roses, the extent of saltiness, or even the maturity of a man. Some properties, such as car speed, height and length, could be accurately measured by means of certain concrete measures. Nonetheless, there are some properties whose extent could not be told accurately by any concrete measurement instruments, i.e. the extent of tiredness, seriousness, etc. As a result, these properties are thought to be more abstract. What is interesting is that through languages, abstract extent of some conditions or actions could be so vividly described that it will bring the listeners' sympathetic responses and make them identify themselves with the situation. How is this done? The magical effect of the linguistic expressions is attractive, and the conceptual structure operated in human cognition is worthy of exploration. The present study works on the excessive construction in Mandarin and degree adverbs in English. By figuring out the differences and commonalities between the two languages, it would be proposed that cognition teaching would benefit to both language learning and teaching.

The data are mostly collected from the google searching engine, and the ones in classical literatures are got from the digital books on websites. Excessive construction composed of a predicate and a complement is a novel use, and its innovation is so speedy that dictionaries fail to catch up. The only term well introduced in dictionaries is $s i$, which has a long history. Google is really a big corpus containing various sources and styles of languages. The data in colloquial language could be collected from personal blogs, BBS, etc.; such expressions are necessary in that the excessive phrases are mostly uttered by the young generation in informal situations to express personal emotions. Basically, the Mandarin data includes both Taiwan Mandarin and Mainland Chinese. The English data are mainly collected from Yahoo dictionary.

\section{EXCESSIVE CONSTRUCTION}

\footnotetext{
* The corresponding author

${ }^{1}$ In this paper, the Mandarin data is shown in the following manner.

我真的忙爆了

wo zhen-de mang bao le

"I'm really extremely busy."

The Chinese characters are at the first line; the second line displays pinyin; the third line presents English translations. Pinyin for each Chinese character is adopted from the version of Xin-Hua Ci-Dian 新華詞典.

${ }^{2} \mathrm{X}$ refers to predicates, usually verbs or adjectives.
} 
In Mandarin, there are various ways to express EXTENT; among them, the use of degree adverbs is the most common. The predicate-complement structure is often used to indicate excessive extent as well, and X-si appears with the highest frequency. In this case, the combination is named "excessive construction" and the complement $s i$ "excessive complement."

1) 我今天累死了

wo jin-tian lei si le

"I'm extremely tired today."

The construction is popular with young people because it has dramatic or exaggerative effect. What is more, the construction is not fixed to some certain components but welcomes a variety of lexical terms to be the complement. In modern Mandarin, beside si, there are many other excessive complements (e.g. bao 爆, fan 翻, etc.) Mostly, the complements are grammticalized from lexical terms referring to negative body parts. Going through all the complements, the study first tries to figure out how the negative body parts are connected to excessive extent in cognition. After that, English degree adverbs indicating excessiveness would be examined to support the cognitive operations.

\section{LITERATURE VIEW}

In recent years, there are more and more studies digging into the so-called "excessive construction". There are papers discussing a certain complement. Some scholars (Wu 1997, Ji 2000, Ho 2005, etc.) focus on the phrase "X+si..." because of its highest frequency, some pay attention to bao (Huang 2008). Others (Qiu 2001, Liu 2003, Li 2005) include more excessive complements to make an overall study.

Qiu (2001): si 死, dai 呆, bi 整, huai 壞

Liu (2003): $j i$ 極, tou 透, si 死, huai 壞

Li (2005): hen 很, $j i$ 極, huai 壞, $s i$ 死

As to the study on excessive X-si phrases, many of the scholars work on the classification of the predicates. Those who study multi-complements focus mainly on the differences among the complements but discuss less about the commonalities. According to Liu (2008), excessive complements are grammaticalized from lexical terms which carry three features: [-count], [negative] and [achievement].

The following chart lists the excessive complements studied before.

\begin{tabular}{|c|c|c|c|c|c|c|c|c|}
\hline $\begin{array}{l}\text { Qiu } \\
(2001)\end{array}$ & $\begin{array}{l}\text { Zhu } \\
(2006)\end{array}$ & Wu (1997) & $\begin{array}{l}\text { Liu } \\
(2003)\end{array}$ & $\begin{array}{l}\mathrm{Ji} \\
(2000)\end{array}$ & $\begin{array}{l}\text { Ho } \\
(2005)\end{array}$ & $\begin{array}{l}\mathrm{Li} \\
(2005)\end{array}$ & $\begin{array}{l}\text { Zhou } \\
\text { (2005) }\end{array}$ & $\begin{array}{l}\text { Wei } \\
(2004)\end{array}$ \\
\hline$s i$ 死 & $s i$ 死 & $s i$ 死 & $s i$ 死 & $s i$ 死 & $s i$ 死 & $s i$ 死 & & $s i$ 死 \\
\hline \multirow[t]{2}{*}{$b i$ 獘 } & $b i$ 整 & & & & & & & $b i$ 獘 \\
\hline & & & & & & & $s a$ 邹 & \\
\hline \multirow[t]{4}{*}{ huai 壤 } & & huai 壤 & huai 壤 & & & huai 壤 & & huai 壤 \\
\hline & & sha 傯 & & & & & & \\
\hline & & fong 瘋 & & & & & & \\
\hline & & mong 蒙 $^{3}$ & & & & & & \\
\hline \multirow[t]{10}{*}{$d a i$ 呆 } & & $d a i$ 呆 & & & & & & $d a i$ 呆 \\
\hline & & & & & & hen 很 & & \\
\hline & & & $j i$ 極 & & & $j i$ 極 & & $j i$ 極 \\
\hline & & & tou 透 & & & & & tou 透 \\
\hline & & & & & & & & bao 爆 \\
\hline & & & & & & & & $d a$ 大 \\
\hline & & & & & & & & bian 扁 \\
\hline & & & & & & & & hun 昏 \\
\hline & & & & & & & & can 慘 \\
\hline & & & & & & & & fan 翻 \\
\hline
\end{tabular}

The present paper excludes $j i$ 極, hen 很, $d a$ 大 and bian 扁. $J i$ and hen originally carry the sense of extent and do not behave like other complements. Da and bian are not included because the examples are too few to reach a systematic analysis.

Basically, there is a difference of the degree of generalization, and si is so highly generalized that it could collocate with the most predicates. Quite the contrary, the newcoming excessive complements are less generalized and appear only with some certain predicates. The aim of the study is to find out the features shared by the lexical terms which are further grammaticalized to excessive complements, so the degree of generalization is not influential.

\section{Cognitive Linguistics}

\footnotetext{
${ }^{3}$ The term is not used in Taiwan Mandarin.
} 
COGNITIVE LINGUISTICS refers to the branch of linguistics that interprets language in terms of the concepts, sometimes universal, sometimes specific to a particular tongue, which underlie its forms. It adheres to three central positions. First, it denies that there is an autonomous linguistic faculty in the mind. Basically, cognitive linguists do not deny that part of the human linguistic ability is innate, but they deny that it is separate from the rest of cognition. Second, it states that grammar is understood in terms of conceptualization and views meaning in terms of the mental spaces. Third, it is claimed that knowledge of language arises out of language use. In other words, language is both embodied and situated in a specific environment.

Based upon Cognitive Linguistics, human linguistic ability and other cognitive abilities are indivisible. Cognitive ability is regarded as the foundation of human knowledge; language construction, language learning and language use should be understood through human cognition. The representatives are Charles J. Fillmore, George Lakoff, Ronald Langacker, Gilles Fauconnier, L.Tammy, etc. Generally, languages do not directly represent or correspond to the real world. There is a "cognitive construction" lying in-between to link linguistic expressions and reality. The intermediate level stores various conceptual structures people construct from their experiences with the real world.



Take TIME as an example. TIME has no explicit border line in the real world, but people say "in three minutes". The preposition in is adopted because TIME is conceptualized as an object with limit. Meanwhile, the container image schema and the IN-OUT image schema are in operation. In our opinions, the conceptual system is basically rooted in five senses, body motions and human's experiences in material and social environments, which could be lumped together as HUMAN EXPERIENCE.

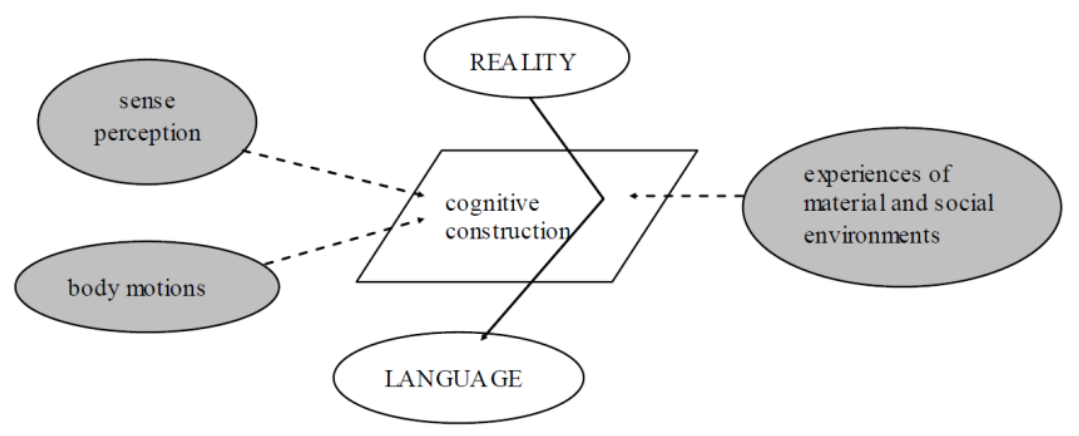

\section{DISCUSSION}

\section{A. Commonalities Shared by Mandarin Excessive Complements}

Up to present, the complements appearing in the excessive construction in Mandarin are $s i$ 死, $b i$ 整, huai 壞, $s a$ 鞄, $s a$ 俊, feng 瘋, dai 呆, gua 掛, hun 昏, can 慘, fan 翻 and bao 爆. Since the construction is quite productive, the number of excessive complement is increasing. Some other lexical words are grammaticalized to be the excessive complement, and the latest terms used by the young people are dian 癲, $\tan$ 瘼保, can 殘, fei 廢 and $c h i$ 疾.

\section{dian 癲 “insane"}

(2) 帥癲了啊 親愛 的 杰倫 (Mainland)

Shuai dian le a qin-ai de Jie-lun

"Dear Jay, you're very handsome."

(3) 那天, 我忙癲了!

Na-tian wo mang dian le

"I was extremely busy on that day."

(4) 我 真 的 快 冷 顛 了那...鼻涕 流的 難 受死 了那...

Wo zhen de kuai leng dian le na bi-ti liu de nan-shou-si le na

"It's really very cold. My running nose makes me very uncomfortable." 
(5) 一聲一聲香甜酥軟的爸爸, 叫的老爸樂顛了, 樂昏了。

Yi-sheng yi-sheng xia-tian shu-ruan de ba-ba jiao de lao-ba le dian le le hun le

"(Her) sweet calling of "pa-pa" made Father very happy."

\section{tan 廠 “paralysis"}

(6) 長 得 超 像 李 俊 基的 簡 直 是 帥 瘔隹了!!

Zhang de chao xiang Lee Jun-ji de jian-zhi shi shuai tan le

“(He) looks very much like Lee Jun-ji...He’s extremely handsome.”

(7) 老 師這幾天快忙瘔隹了, 又要考試, 國語日報又一直催稿 (Taiwan)

Lao-shih zhe ji tian kuai mang tan le yiu yao kao-shih guo-yu-ri-bao yiu yi-zhih cui-gao

"The teacher is extremely busy these days. She has to give exams to students, and Mandarin Daily News hurried her to give the manuscript."

(8) 一 想 到 還 有 壓歲 錢 可以拿你 就樂 瘼了..

Yi xiang dao hai-yiu ya-sui-qian ke-yi na ni jiu le tan le

"You're extremely happy about getting red envelops."

(9) 馬大 和 小黑 在路邊 等了我牛 小時, 已經冷瘼了

Ma-da han xiao-hei zai lu-bian deng le wo ban xiao-shi yi-jing leng tan le

"Since Mark and Black have waited for me for half an hour beside the road, they are freezing."

can 殘 “cripple"

(10) 帥殘了的 羅 志祥! !

Shuai can le de Luo Zhih-xiang

"How handsome Luo Zhih-xiang is!"

(11) 姐姐, 最近忙殘了

Jie-jie zui-jin mang can le

"Dear sister, I'm awfully busy recently."

(12) 笑 翻了, 樂殘了!

Xiao fan le le can le

"(We) are laughing to death, we're very happy."

(13) 本人也冷殘了, 一下雪就 1 星期.

Ben-ren yie leng can le yi xia-xue jiu yi xing-qi

"It has been snowing for one week. I'm very cold."

(14) 忙碌 的牛周結束了, 累殘了...

Mang-lu de ban-zhou jie-shu le lei can le

"The busy half-week comes to the end, and I'm very tired..."

$f e i$ 廢 “disabled”

(15) 放 假 前 的諸多 事情, 感 覺自己都要 忙廢了。

Fang-jia qian de zhu-duo shih-qing gan-jue zi-ji dou-yao mang fei le

"There is a bundle of things to be done before the vacation, I'm extremely busy."

(16) 有 酒友 則香 大家 樂廢了..

Yiu jiu-yiu ze xiang da-jia le fei le

"Everyone is extremely happy to have buddies to enjoy the wine."

(17) 天 氣冷 廢了

Tian-qi leng fei le

"It is extremely cold."

chi 疾 "idiot"

(18) 帥呆了! 帥痴了! 他越來越師了!

Shuai dai le shuai chi $\overline{l e}$ ta yue lai yue shuai le

"How handsome he is! He's getting more and more handsome."

(19) 哈哈, 我 樂疾了。

Ha-ha wo le chi le

"Ha-ha! I'm extremely happy."

The predictability of these new-coming complements is so weak that they are only fixed to some certain predicates. After a careful study, we find that the excessive complements are mainly derived from four types of lexical words.

1. DEATH ( $s i$ 死, $b i$ 整, gua 掛, huai 壞, $s a$ 急)

2. ABNORMAL MENTAL CONDITION (feng 瘋, dai 呆, chi 痴, dian 癲)

3. ABNORMAL PHYSICAL CONDITION ( hun 昏, yun 量, tan 癱, fei 廢, can 殘)

4. OTHER (fan 翻, bao 爆, can 慘) 
Literally, most of these words indicate basic or possible experiences of the body. In fact, however, many people have not experienced the conditions yet and they even do not want to have any of the experiences. As a result, they understand and value the experiences through others'. All the experiences included in the four types are quite terrible, so the negative value is given. Human beings are afraid of death in that it strands for unexistence; as a result, DEATH is regarded the most terrible experience among all. The combination of mentality (soul) and body together constitutes a human being, and the abnormality of either one would bring about a threat to the person. As a result, the loss of perception and physical function is positioned at the top of dread scale. Explosion and turnover appear not that terrible as death. Nonetheless, in terms of Liu (2008), since the two incidents might bring the cost of one's life, they are thought to be very serious.

\section{B. English Excessive Degree Adverb}

It is found that negative bodily experiences are easily linked to excessive extent. The generalization found in Mandarin seems to be applicable in English as well. In English, deadly plays the role of an excessive degree adverb. In addition, the phrase "V to death" signifies the extremity of a condition.

He was tired to death after a day's work.

I'm busy to death.

However, English prefers degree adverbs to V-to-death construction. Consequently, degree adverbs appear much more frequently. Since there is a variety of excessive degree adverbs in English, an overall study is necessary to find out a generalization. First, a classification would be made based upon the literal meaning of the terms from which the excessive adverbs are derived. After that, a comparison between Mandarin and English is held to see whether the two languages have the same cognitive operations. By doing this, languages universal would be found. Basically, degree adverbs which are not derived from lexical terms (i.e. very) would be excluded.

According to our data, English words of the following types could become excessive adverbs through suffixation, i.e. the addition of the suffix $-l y$.

\section{DEATH}

deadly: deadly dullness

\section{DREAD}

awfully: You're awfully nice to me.

terribly: I'm terribly sorry.

fearfully: He is fearfully busy.

dreadfully: I'm dreadfully busy.

frightfully: I am frightfully sorry.

horribly: Everything has gone horribly wrong.

shockingly: My sandwich is shockingly good today

\section{MISERY}

miserably: They were miserably poor.

woefully: I am woefully sorry for Iraqis.

\section{PAIN}

painfully: He was painfully shy because of his shabby clothes and down-home ways.

sorely: We shall miss her sorely.

bitterly: It is bitterly cold today.

piteously: But in proportion to Beijing's population, the figure is piteously low, probably the lowest compared to other capitals in the world.

cruelly: The job was cruelly difficult.

\section{SORROW}

lamentably: The bonus CD is lamentably sparse.

sadly: But, in this case, the apparent militancy behind the comment is sadly funny.

grievously: The voice is grievously happy.

\section{OUT OF EXPECTATION}

surprisingly: It was surprisingly cheap.

astonishingly: Your English is astonishingly good.

incredibly: I felt incredibly embarrassed.

\section{OTHERS}

bloody: It's bloody wonderful!

badly: She wants to go badly.

Quite similar to Mandarin, English uses terms with negative connotations to indicate excessive extent. At first sight, the negative experiences adopted in English are not that concrete as those in Mandarin. Physical experiences are concrete; comparatively, the English terms refer to abstract psychological experiences. However, the abstract experiences adopted in English are often experienced in one's life, and people have no difficulty in understanding them. Contrarily, the concrete bodily experiences adopted in Mandarin are not experienced by everyone, and it possibly is human's dread of the negative experiences that brings about the derivation of excessive sense. Actually, it is not 
surprising that dread is linked to excessive extent in Mandarin. In the following sentence, ke-pa "dread" indicates excessiveness itself.

人多到很可怕

Ren duo dao hen ke-pa

"There are so many people."

\section{The Linking in Cognition}

a. Why Bodily Experiences Related

Human beings are born with a body, and they use the body to experience everything and know the real world. The body then is projected to the outside world; as a result, many objects become human beings through metaphor and possess body parts, such as shan-tou /頭 “the tope of the mountain”, shan-yao //腰 “the mountainside”, shan-jiao // 腳 “the foot of a mountain”. Such a people-oriented phenomenon is well seen in metaphorical expressions. To speak strictly, except some subtle differences (i.e. color of eyes/hair/skin, weight, height), every human body is constructed of the same types of body parts and internal organs. Then, what is experienced from the body is universal. In our opinions, the adoption of universal bodily experiences would ease communication. What is more, extent is quite abstract, and it is quite natural that people use concrete bodily experiences to understand extent. The adoption of bodily experiences is language-universal, but the choice of terms is language-specific. Mandarin excessive complements are mostly derived from words referring to abnormal body conditions while English prefer terms related to emotions such as sorrow, pain, misery and dread.

b. Why Negative

According to the discussion above, it is not difficult to find that both Mandarin and English adopt negative experiences, especially those that would bring a threat to the human body, to indicate excessive extent. Actually, many other languages have the same linguistic phenomenon. By and large, both the most positive terms and the most negative ones could derive the sense of excessiveness in that they indicate the extremity of a condition and would be positioned at the two extremities of a scale ${ }^{4}$ in cognition.

However, negative terms usually bring great impact than their affirmative counterparts, and it seems to be a tendency that negative terms are more likely linked to extent than positive ones.

Why are lexical terms carrying negative connotations more easily adopted to express excessive extent? The frequency of use matters to some extent. Basically, the high frequency of use will eliminate the magic power of a word. Positive terms are heard all the time, and people might gradually treat their appearance as normal. Quite different, people always feel more interested in things which are rarely seen. In the same way, linguistic expressions that are seldom heard catch the audience's attention more easily. Since negative words are forbidden in public and rarely uttered, they would bring about an unimaginable effect. In consequence, the function of exaggeration is achieved.

c. Paradoxical Combination

Taking a negative term to be excessive degree adverb would bring about an interesting phenomenon. A paradoxical combination arises when the negative term appears with a positive adjective. The same phenomenon appears when an adverb derived from a positive lexical term modifies a negative adjective.

awfully excellent

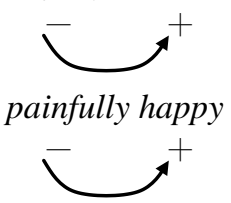

You can hear it in every guitar strum, and with the woefully beautiful pitch of his voice.

perfectly terrible
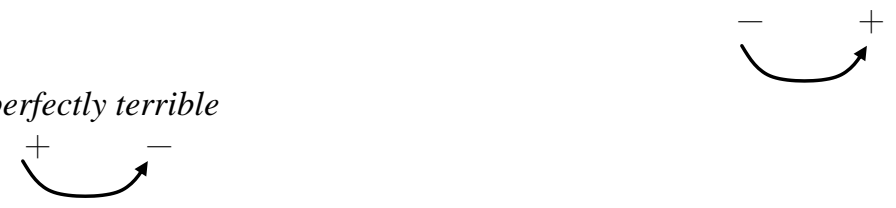

A reader or listener would have difficulty in comprehending the phrase if he/she has no idea that the negative terms represent excessive extent. In our opinions, such a paradoxical combination would require more time for language processing.

\section{CONCLUSION}

\footnotetext{
4 There is scale image in human's concept.
} 
A language is not merely a language but reflects the cognitive system in human mind. Always, cognition is constructed based upon the experiences of the reality (real world). Nonetheless, as what is mentioned before, the relation of language to experience is not that direct but requires cognitive operations as the intermediate medium. Therefore, cognition teaching is necessary for language teaching.

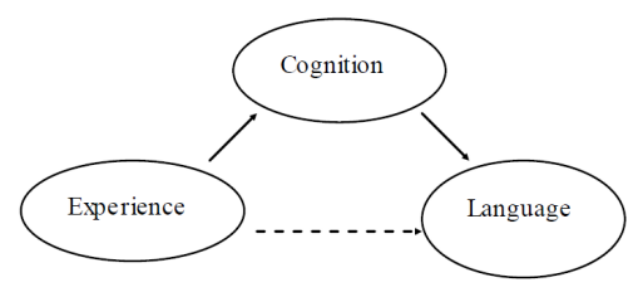

Different cultures would have different experiences, which will then make differences in cognition and bring out different linguistic uses. This is language diversity. In addition to language diversities, there are language universals existing, especially those linguistic expressions regarding basic bodily experiences. Basically, language diversity and language universal complement each other to benefit foreign language learning. Language specific would help the learners to know clearly about a certain culture while language universal might decrease the burden of memorizing. The commonality shared by English and Mandarin in expressing excessive extent is found in this paper. Briefly, negative bodily experiences (i.e. death, dementia, being cripple, dread and etc.) are valued negative in human's cognition and stand for the end of a scale, which then link to excessive complements or degree adverbs in languages.

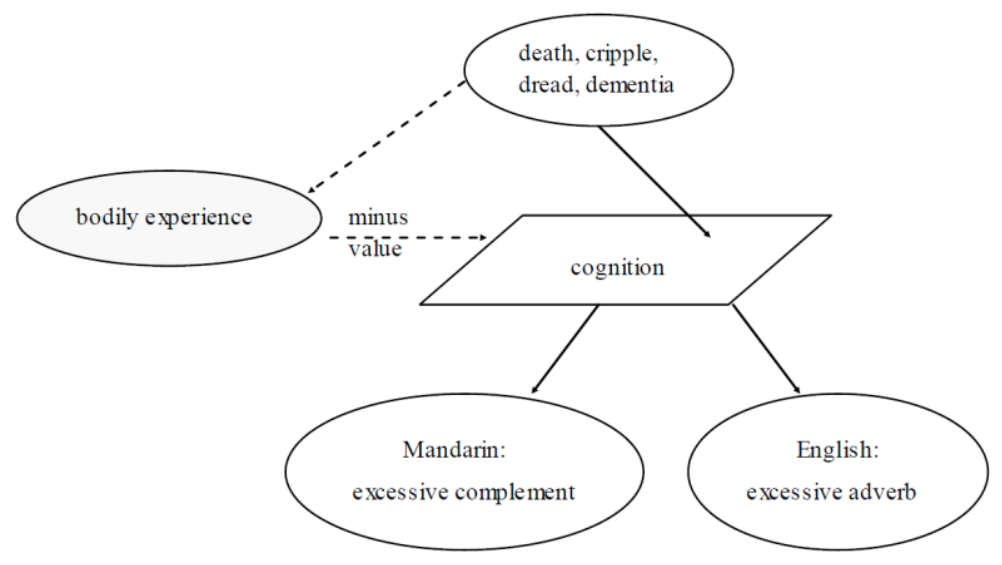

\section{REFERENCES}

[1] Chi, Y. (1998). Tan Hanyu Si de Xiuci Gongneng (On the rhetoric function of Mandarin SI), Journal of Liaoning Normal University (Social Science), No. 6, 58-60.

[2] Croft, William \& Cruse, Alan D. (2004). Cognitive Linguistics. Cambridge Textbooks in Linguistics.

[3] Fauconnier, Gilles. (1997). Mappings in Thought and Language. Cambridge University Press.

[4] GOLDBERG, A. E. (1995). Constructions: A construction grammar approach to argument structure. Chicago: University of Chicago Press.

[5] Hopper, P. \& Traugott, E. (1993). Grammaticalization. Cambridge, UK: Cambridge University Press.

[6] Ho, R. (2005). "Dong (Xing) + Si +..." de Jiegou Yuyi Fenxi (A Semantic Analysis of "V (Adj.) + SI + ..." Construction, Journal of Beijing Institute of Education, Vol. 19, No. 2, 16-21.

[7] Huang, Y. (2008). Xiandai Hanyu Bao de Yongfa Ji Qi Yufahua Licheng (A Study of Grammaticalization of Chinese BAO), Chinese Linguistics in Leipzig. Edited by Redouane DJAMOURI, Barbara MEISTERERNST \& Rint SYBESMA.

[8] Ji, Y. (2000). "Xiang-si wo le" han "Xiang-si ni le" (I Miss You a lot), Journal of Tianjin Normal University (Social Science), No. 2, 78-80.

[9] Li, Y. (2005). Chengdu Fuci "hen”, “ji”, “si”, "huai” de Yianjiu (The Study of Degree Adverb hen, ji, si and huai), M.A. Thesis, Shanghai Normal University.

[10] Liu, H. (2008). A study of the Excessive Construction I Modern Taiwan Mandarin. PH.D. Dissertation. Hsinchu: National Tsing-Hua University.

[11] Liu, L. (2003). Xiandai Hanyu Jixin Chengdu Buyu Chutan (A Preliminary Study on Excessive Complements in Modern Chinese), Journal of Beijing Normal University, No. 6, 115-120.

[12] Qiu, D. (2001). Kouyu Zhong Pubian You Teshu de Buyu Leixing-- Ganshou Chengdu Buyu (A common but Unique Type of Complement in Spoken Language: of Feeling Intensity Complement), Journal of Guangzhou University, vol.15, 59-62.

[13] Tsao, F. Tsai, L. \& Liu, H. (2001). Shenti Yu Piyu: YuyianYu Renzhih de Shouyao Jiemian (Body and Metaphor: The Primary Medium of Language and Cognition). Taipei: Crane Publishing Co. 
[14] Wei, Y. (2004). [Xiandai Xin Yuyian] Shuaidao Buxing - Tan Liuxing Yongyu de Kuazhang Xingrong Yongfa (The Latest Exaggerated Expressions in Chinese). http://www.lungteng.com.tw/publish/Newpaper/002/chinese/16.htm (accessed 19/5/2004).

[15] Wu, C. (1997). Kouyu Jushi "W si le" de Yuyi Yufa Tedian (Semantic and Syntactic characteristics of "W SI le" in Spoken Language), Journal of Northeast Normal University (Philosophy and Social Sciences), No.1, 71-75.

[16] Zhou, X. (2005). Chengdu Buyu Ju "V/A sha" Shi de Laiyuan Ji Qi Yianbian (The Diachronic Evolution of Extent "V/A sha"), Academic Exchange, Vol. 7, 138-142.

[17] Zhu, S. (2006). Chengdu Buyu Jixing Yiyi de Huode-Yi Si Lei Ci Weili (The Acquisition of the Extreme Meanings in Degree Complements-An Example of the Group of Relevant Phrases about "Death"), Journal of Wenzhou Teachers College, Vol. 27, No. 6, 26-30.

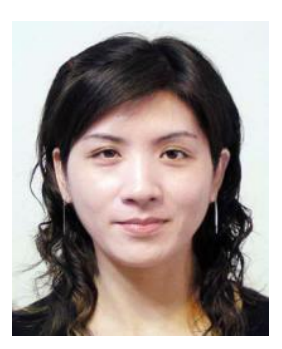

Hsiu-Ying Liu (b. 1972, Kaohsiung, Taiwan) received her PH. D. in Linguistics from National Tsing-Hua University, Taiwan in 2008.

She is currently an associate professor in the department of Foreign Languages and Literature, Asia University, Taichung, Taiwan. Her research interests include language teaching and acquisition, cognitive linguistics, semantics and pragmatics.



Cheng-Chung Kuo (b. 1972, Taichung, Taiwan) received his DBA from University of South Australia, Australia in 2004.

$\mathrm{He}$ is currently an associate professor in the department of Cultural and Creative Industries, National Taichung University, Taichung, Taiwan. His research interests include cognitive psychology, design semantics and product design. 